\title{
Illumination and Aeration Compared with Application of Combined Adsorbent for Purification of Grey Water as a New Available Source (Laboratory Scale)
}

Morteza Badkouby*

Department of Irrigation and drainage, Fasa University of Medical Science, Iran

"Corresponding author: Morteza Badkouby, Department of Irrigation and drainage, Fasa University, Iran, Tel: +987153344849; E-mail: Morteza.badkouby. 70@gmail.com

Received date: July 25, 2018; Accepted date: August 13, 2018; Published date: August 20, 2018

Copyright: ( $\odot 2018$ Badkouby M. This is an open access article distributed under the terms of the Creative Commons Attribution License, which permits unrestricted use, distribution and reproduction in any medium, provided the original author and source are credited.

\section{Retraction Note:}

\The article entitled "Illumination and Aeration Compared with Application of CombinedAdsorbent for Purification of Grey Water as a New Available Source (Laboratory Scale)" has been accepted for publication in the International Journal of Waste Resources considering the statements provided in the article as personal opinion of the author which was found not having any conflict or biasness towards anything. As the article was a perspective one, information provided by the author was considered as an opinion to be expressed through publication.

Publisher took decision to make the article online solely based on the reviewers suggestion which considered the article not but a personal opinion of the author. However, it is found that the author have some personal concerns and issues, therefore, being retracted from the journal. 